\title{
LAS EXPORTACIONES DEL LITORAL ARGENTINO AL PUERTO DE BUENOS AIRES ENTRE 1783 Y 1850*
}

ROBERTO SCHMIT

Instituto Ravignani-UBA

MIGUEL A. ROSAL

Instituto Ravignani-CONICET

\section{RESUMEN}

En este trabajo estudiamos la dinámica de las exportaciones del Litoral argentino con el puerto de Buenos Aires entre los años de 1783 a 1850 . A partir del análisis cuantitativo del comercio litoraleño evaluamos su comportamiento y composición, lo que nos permite sostener que las exportaciones crecieron más rápidamente después de la independencia que durante el período colonial, y por tanto también el conjunto de la economía litoraleña. Así, esta región habría experimentado una transición económica relativamente exitosa entre el periodo colonial y la etapa independiente.

\section{ABSTRACT}

This article studies the dynamics of exports from the Argentine Litoral to Buenos Aires between 1783 and 1850. A quantitative analysis of the litoral's commerce enables us to state that exports grew faster after independence than during the colonial period, as did the «litoraleña» economy as a whole. As a result, the region experienced a successful transition from the colonial period to independence.

* Agradecemos los comentarios de José Carlos Chiaramonte y Enrique Tandeter, así como los efectuados por los árbitros anónimos de la RHE. 


\section{INTRODUCCIÓN}

El análisis de los efectos económicos ocurridos desde fines de la época colonial y durante principios del periodo independiente en Hispanoamérica ha mostrado una situación desalentadora en numerosas regiones del espacio en cuestión. En general hay acuerdo que en lo inmediato no se hicieron sentir los beneficios de los movimientos independentistas y sí las consecuencias negativas de las guerras y conflictos que los mismos trajeron aparejadas. Más aún, en buena parte de las ex colonias esas funestas secuelas perduraron hasta mediados del siglo XIX ${ }^{1}$. Así, por ejemplo, en Perú se registra un agudo decaimiento de la producción minera y una crisis prolongada en la agricultura; por lo cual las condiciones para el crecimiento llegarían hacia 1850 en que aparece una economía moderna de exportación con el guano. En México, por su parte, según el estado de la minería, la balanza de pagos y la deuda pública, el crecimiento de la economía fue pequeño, al mísmo tiempo que no aumentó la capacidad productiva ${ }^{2}$. En cuanto al desempeño económico argentino parecería ser uno de los casos más exitosos de transición económica entre la colonia y el período independiente. Precisamente en este artículo aportamos nueva evidencia para el análisis de ese proceso, tomando como sujeto de estudio al Litoral argentino entre 1783 y $1850^{3}$.

El Litoral argentino, comunmente llamado la Mesopotamia, se encuentra situada entre los ríos Paraná y Uruguay; es una gran llanura cortada en algunas zonas por lomadas entre numerosas lagunas y esteros que presentan una escasa elevación sobre el nivel de los ríos [confrontar mapa]. Esta región, tempranamente colonizada por los españoles, contó con la ventaja de que tanto el río Paraná como el Uruguay - los cuales desembocan en el Río de la Plata - eran navegables por medianas embarcaciones desde el norte de la provincia de Corrientes. Estas vías fluviales permitieron vincular desde el siglo XVI las producciones litoraleñas al espacio económico peruano-rioplatense que tenía como eje a la ruta Lima-Potosí-Buenos Aires $^{4}$. De esta manera el Litoral se convirtió en una importante zona de la circulación comercial interregional que lo unía a Paraguay, Buenos Aires, Tucumán y el Alto Perú. Ya a comienzo del siglo XVII Santa Fe funcionaba como productora,

Ver por ejemplo Halperin Donghi (1985) y (1986), Liehr (ed.) (1989), Leslie Bethell (ed.) (1991) y Prados de la Escosura y Amaral (eds.) (1993).

2 Ver por ejemplo: Coatsworth (1990); Salvucci, R., y Salvucci, L. (1993); Bonilla (1981); Gootenberg (1989); Quiroz (1993).

${ }^{3}$ Denominamos Litoral o región litoraleña a las actuales provincias de Corrientes, Entre Ríos y Santa Fe.

4 Sobre el funcionamiento de ese amplio espacio económico, ver Assadourian (1983 a) y Tandeter, Milletich, Schmit (1994). 
depósito y centro redistribuidor de cantidades considerables de ganado en pie, mulas y yerba mate 5 .

Durante el siglo XVIII la relación del Litoral con los mercados regionales se acrecentó. Pero en la segunda mitad del siglo la producción ganadera que tenía como destino a ultramar cobró mayor dinámica, por lo cual se fortaleció aún más el nexo mercantil de esta región con el puerto de Buenos Aires. Estos perfiles de producción y circulación se acentuaron todavía más desde comienzo del siglo XIX dada su definitiva inclinación hacia el mercado atlántico.

\section{MAPA 1}

Principales ciudades y puertos del litoral argentino

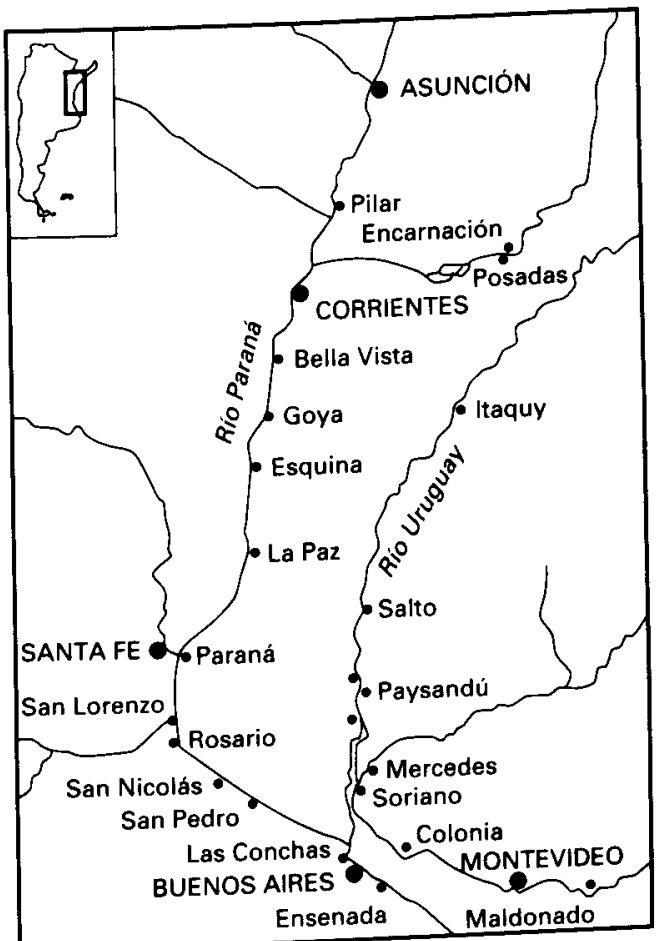

Fuente: Vera Blinn Reber, British Mercantile Houses in Buenos Aires. 1810-1880. Harvard University Press, Londres, 1979.

'El rol y la importancia mercantil que adquirió desde fecha temprana la región rioplatense están expuestas en: Moutokias (1988), pp. 46-73. Cfr. también (mimeo, 1992). Sobre la producción y circulación de la yerba mate se puede consultar el importante trabajo de Garavaglia (1983). 
En la era independiente se quebró el eje Potosí-Buenos Aires, sobre el cual giraban las economías regionales rioplatenses; esta ruptura perjudicó a algunas de las mismas, obligando a que su comercio se reorientara hacia otros mercados ${ }^{6}$. El Litoral, en cambio, mantuvo la fuerte vinculación económica con Buenos Aires, sobre todo debido a la negativa de esta última de permitir la libre navegación de los ríos interiores, reservándose de ese modo el rol de intermediaria entre las regionesprovincias y los mercados doméstico y ultramarino. Dados los estrechos vínculos mercantiles entre el Litoral y Buenos Aires, tomamos como indicador las exportaciones de aquella región a la aduana porteña, con el objetivo de analizar la evolución económica litoraleña desde fines del siglo XVIII hasta mediados del siglo XIX. Así, en este estudio tratamos de brindar un panorama complementario de aquéllos presentadas por otros estudiosos de la cuestión ${ }^{7}$.

\section{LOS ESTUDIOS SOBRE EL LITORAL ARGENTINO}

Diversas investigaciones han mostrado el progreso del Litoral desde fines del siglo XviII. Entre ellas se destaca el estudio de Tulio Halperin Donghi que ha marcado el rápido avance de la región hacia finales de esa centuria; pero éste habría sido un avance parcial en medio de penosos reajustes, por lo cual no sería sino el momento inicial de un proceso irreversible, que recién a lo largo del siglo XIX remodelaría el panorama del litoral rioplatense ${ }^{8}$.

Posteriormente, el trabajo sobre los diezmos de Juan Carlos Garavaglia ha demostrado que entre 1786 y 1802 esta región en su conjunto tuvo un evidente crecimiento. Aunque debemos tener en cuenta, como el mismo autor señala, que ese comportamiento no tocaba por igual a todas las áreas de aquel espacio. Si se analizan los cortes temporales realizados en el trabajo se observa que entre 1788 . 1792 el predominio fue casi exclusivo de Buenos Aires, mientras que el Litoral se mantenía estable. Pero en el lapso de 1798-1802 se dio un avance fulgurante de dicha región, cuya masa decimal nos muestra una supremacía de la ganadería?

También Claudia Wentzel en su examen de las exportaciones litoraleñas de fines del siglo XVIII ha corroborado ese crecimiento. Para la autora, el Litoral es una

- En cuanto a la región del noroeste del actual territorio argentino se volcó hacia el nuevo mercado peruano-boliviano, mientras que la región de Cuyo se inclinó hacia los mercados del Pacífico. Langer (1987); Langer y Conti (1991); Conti (1989, 1992 y 1993) y Segreti (1981).

El presente trabajo se basa en recientes investigaciones efectuadas por los autores: Schmit (1991) y (1993). Y Rosal (1992 a), (1992 b), (1993 a), (1993 b) y (1994).

${ }^{\&}$ Halperin Donghi (1972), pp. 15 y $27-31$.

${ }^{9}$ Garavaglia (1987). 
de las áreas más importantes de todas las participantes en el mercado de Buenos Aires ${ }^{10}$.

En lo que se refiere a la evolución económica del Litoral después de la revolución, Miron Burgin sostiene que las perspectivas económicas abiertas luego de 1810 eran tan brillantes para las provincias litoraleñas como para Buenos Aires. Pero en verdad el progreso económico de aquéllas fue desalentador comparado con el de esta última, ya que las reformas no pasaron de la apertura de Buenos Aires al comercio exterior ${ }^{11}$.

Por su parte, los trabajos de Halperin Donghi, postulan que las guerras de la independencia, y más tarde las civiles, fueron portadoras del saqueo y la destrucción de la riqueza. Por lo cual, las provincias de esta región sufrieron durante varias décadas las consecuencias de los enfrentamientos políticos de aquellos años ${ }^{12}$. En cambio, este autor ha enfatizado que la provincia de Buenos Aires fue el único caso en el espacio rioplatense que experimentó a partir de 1820 un crecimiento económico significativo ${ }^{13}$.

El estudio más reciente de José Carlos Chiaramonte muestra una imagen algo diferente al referirse al caso de la provincia de Corrientes para las décadas de 1820-40. El mismo plantea que los correntinos lograron recuperarse más tempranamente de los desajustes producidos por los sucesos revolucionarios, lo que les permitió sostener un proceso de fortalecimiento estatal y de lento crecimiento de sus actividades económicas ${ }^{14}$.

Pero, no obstante lo valioso de todos estos aportes, tanto de aquellos que abordaron el estudio de los circuitos mercantiles interregionales como el del desempeño de las producciones rioplatenses decimonónicas ${ }^{15}$, hasta el momento carecemos de un estudio cuantitativo como el que aquí nos proponemos realizar, que analice la situación a largo plazo permitiendo evaluar los efectos económicos ocurridos en el Litoral desde fines del siglo XVIII hasta mediados del XIX.

\section{EXPORTACIONES DEL LITORAL A BUENOS AIRES}

Las exportaciones del Litoral muestran un crecimiento en los valores desde 1783 hasta 1815 , con una caída desde 1816 hasta 1825; finalmente entre 1826 y

10 Wentzel (1987).

$"$ Burgin (1960), pp. 165-168.

12 Halperin Donghi (1972), pp. 15 y 27-31, y (1980), pp. 182-184 y 294-295.

${ }^{13}$ Halperin Donghi (1963).

14 Chiaramonte (1991).

15 También contamos con los estudios para Córdoba, provincias centrales y Cuyo, realizados por Assadourian (1983 b); Palomeque (1989) y Amaral (1990), respectivamente. 
1850 se dio un alza sostenida en los valores comercializados. Así, de acuerdo a las cifras del tráfico, durante el período colonial se produjo un permanente ascenso en el comercio litoraleño, que continúa aún en los años posteriores a la Revolución de 1810 y hasta 1815 . Entonces, parecería que sólo durante unos años se hicieron sentir los efectos negativos de las guerras de independencia, sobre todo en la producción ganadera, por lo cual hubo una caída en los valores comerciales desde 1816 hasta 1825 . A partir de 1826 y hasta 1850 comenzaria una nueva etapa de alza sostenida en el ritmo del comercio litoraleño a Buenos Aires.

\section{GRÁFICO I}

Comercio del Litoral a Buenos Aires, 1783-1850

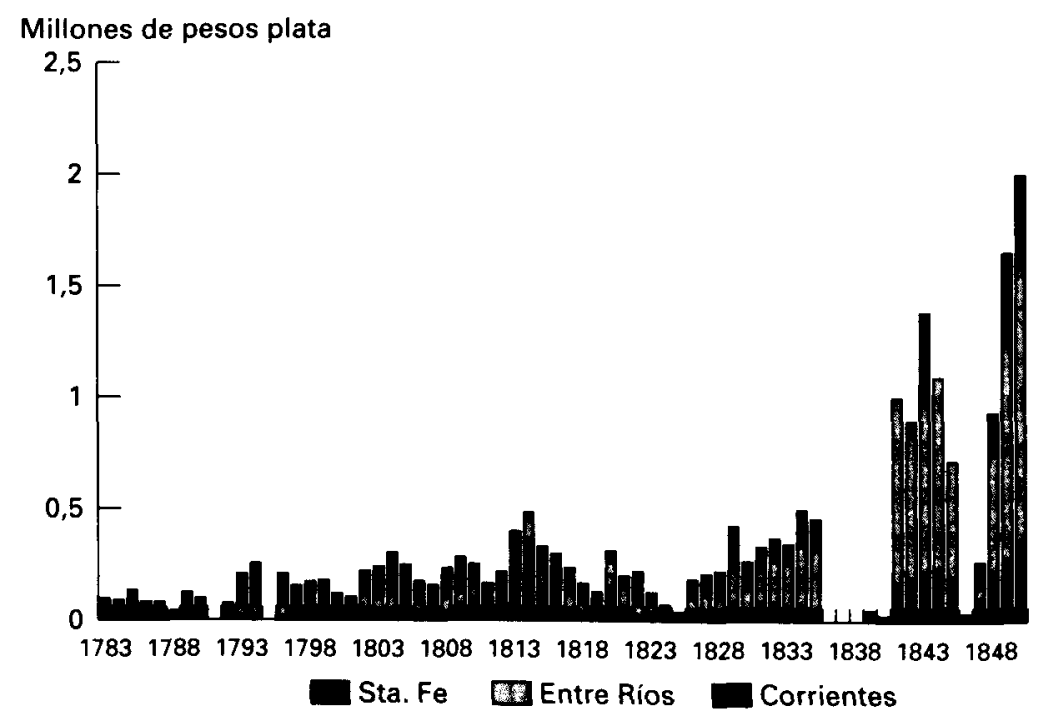

Dentro de estos lapsos de alzas y bajas hay que tener en cuenta el efecto coyuntural negativo que tuvieron sobre la demanda de los productos pecuarios los bloqueos al puerto de Buenos Aires en el período independiente. Así, los valores comerciales denotan grandes saltos y se vieron disminuidos entre 1825 y 1828 por el bloqueo brasileño; más tarde, entre 1838 y 1840, por el francés, y finalmente, entre 1845 y 1848 , por el anglo-francés.

En cuanto a la participación de cada provincia en el comercio total del Litoral, éste fue desigual; durante el período colonial fue mayor el peso del comercio san- 


\section{CUADRO 1}

Valor de las exportaciones de las provincias del Litoral a Buenos Aires, 1783-1850 (en pesos plata)

\begin{tabular}{|c|c|c|c|c|}
\hline & Santa Fe & Entre Rios & Corrientes & Total \\
\hline $1783 \ldots \ldots . .$. & 10.079 & 1.405 & 85.870 & 97.354 \\
\hline 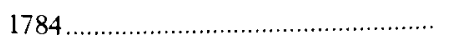 & 35.254 & 1.035 & 53.568 & 89.857 \\
\hline 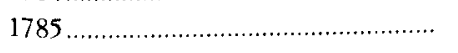 & 54.119 & 3.750 & 77.442 & 135.311 \\
\hline $1786 \ldots \ldots \ldots \ldots \ldots \ldots \ldots$ & 34.073 & 8.118 & 41.357 & 83.548 \\
\hline 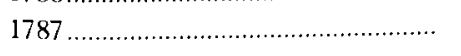 & 31.571 & 4.370 & 47.343 & 83.284 \\
\hline 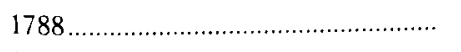 & 7.513 & 6.518 & 28.776 & 42.807 \\
\hline 1789 & 20.061 & 25.785 & 78.941 & 124.787 \\
\hline 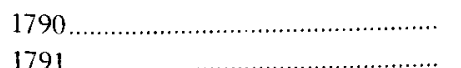 & 15.337 & 20.212 & 62.905 & 98.454 \\
\hline 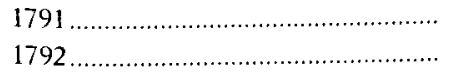 & & & 45.702 & 76.332 \\
\hline $\begin{array}{l}1792 \ldots \\
1793 \ldots\end{array}$ & 17.244 & $\begin{array}{l}13.386 \\
37.490\end{array}$ & $\begin{array}{r}45.702 \\
150.145\end{array}$ & 207.307 \\
\hline 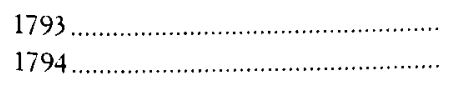 & 19.672 & $\begin{array}{l}37.490 \\
41.982\end{array}$ & 189.505 & 254.899 \\
\hline 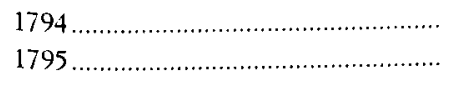 & 23.412 & & & \\
\hline 1796 & 19.260 & 43.358 & 145.129 & 207.747 \\
\hline 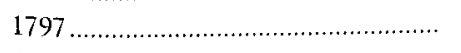 & 13.096 & 18.465 & 122.504 & 154.065 \\
\hline $1798 \ldots \ldots \ldots \ldots \ldots \ldots \ldots \ldots \ldots \ldots \ldots \ldots \ldots$ & 8.676 & 23.601 & 140.201 & 172.478 \\
\hline $1799 \ldots \ldots \ldots \ldots$ & 28.915 & 15.303 & 135.333 & 179.551 \\
\hline $1800 \ldots \ldots \ldots$ & 18.679 & 17.707 & 84.175 & 120.561 \\
\hline 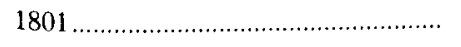 & 29.326 & 7.840 & 67.092 & 104.258 \\
\hline $1802 \ldots \ldots \ldots \ldots \ldots \ldots \ldots \ldots \ldots$ & 48.305 & 66.134 & 106.194 & 220.633 \\
\hline $1803 \ldots \ldots \ldots \ldots \ldots$ & 46.544 & 53.925 & 140.701 & 241.170 \\
\hline $1804 \ldots \ldots \ldots \ldots \ldots$ & 48.618 & 63.823 & 192.350 & 304.791 \\
\hline $1805 \ldots \ldots \ldots \ldots$ & 38.393 & 37.246 & 173.375 & 249.014 \\
\hline 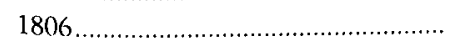 & 41.500 & 33.979 & 100.684 & 176.163 \\
\hline 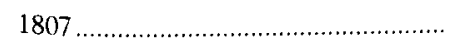 & 25.495 & 20.433 & 111.708 & 157.636 \\
\hline $1808 \ldots \ldots$ & 38.775 & 64.250 & 129.173 & 232.198 \\
\hline 1809 & 61.031 & 59.946 & 161.514 & 282.491 \\
\hline $1810 \ldots \ldots$ & 97.732 & 53.672 & 100.628 & 252.032 \\
\hline 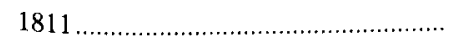 & 73.552 & 15.978 & 76.990 & 166.520 \\
\hline $1812 \ldots \ldots \ldots \ldots \ldots \ldots \ldots$ & 153.549 & 22.673 & 40.666 & 216.888 \\
\hline 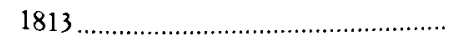 & 350.543 & 16.670 & 30.333 & 397.546 \\
\hline $1814 \ldots \ldots \ldots \ldots \ldots$ & 352.455 & 87.692 & 40.721 & 480.868 \\
\hline 1815 & 138.092 & 90.700 & 100.359 & 329.151 \\
\hline $1816 \ldots \ldots \ldots \ldots \ldots \ldots$ & 153.155 & 26.207 & 118.214 & 297.576 \\
\hline 1817 & 49.359 & 66.943 & 120.899 & 237.201 \\
\hline 1818 & 36.505 & 38.964 & 91.694 & 167.163 \\
\hline 1819 & 38.181 & 29.496 & 60.137 & 127.814 \\
\hline 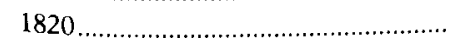 & 131.776 & 128.035 & 51.798 & 311.609 \\
\hline 1821 & 67.113 & 83.039 & 48.925 & 199.077 \\
\hline $1822 \ldots$ & 22.899 & 53.454 & 144.767 & 221.120 \\
\hline
\end{tabular}


CUADRO 1 (continuación)

\begin{tabular}{|c|c|c|c|c|}
\hline & Santa Fe & Entre Rios & Corrientes & Total \\
\hline $1823 \ldots \ldots \ldots$ & 33.219 & 35.319 & 57.549 & 126.087 \\
\hline $1824 \ldots$ & & & 71.390 & 71.390 \\
\hline $1825 \ldots \ldots$ & & & 40.610 & 40.610 \\
\hline 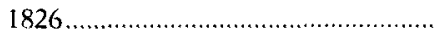 & 52.143 & 47.368 & 84.550 & 184.061 \\
\hline 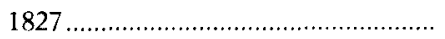 & 45.444 & 72.283 & 90.616 & 208.343 \\
\hline $1828 \ldots \ldots \ldots \ldots$ & 53.551 & 44.216 & 124.559 & 222.326 \\
\hline 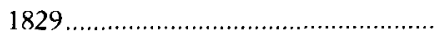 & 82.779 & 135.059 & 203.169 & 421.007 \\
\hline 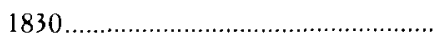 & 48.944 & 98.464 & 117.394 & 264.802 \\
\hline 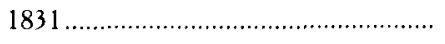 & 84.491 & 141.468 & 104.386 & 330.345 \\
\hline 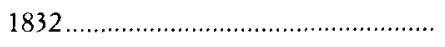 & 77.362 & 192.376 & 98.953 & 368.691 \\
\hline 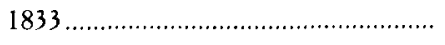 & 59.175 & 198.881 & 85.841 & 342.897 \\
\hline 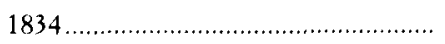 & 66.022 & 277.334 & 150.191 & 493.547 \\
\hline $1835 \ldots \ldots \ldots \ldots$ & 57.038 & 259.411 & 137.672 & 454.121 \\
\hline \multicolumn{5}{|l|}{1836} \\
\hline \multicolumn{5}{|l|}{$1837 \ldots \ldots \ldots$} \\
\hline \multicolumn{5}{|l|}{$1838 \ldots$} \\
\hline $1839 \ldots \ldots \ldots$ & 23.410 & 21.608 & 6.725 & 51.743 \\
\hline 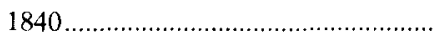 & 13.144 & 12.133 & 0 & 25.277 \\
\hline 1841 & 165.087 & 819.066 & 7.742 & 991.895 \\
\hline $1842 \ldots \ldots \ldots \ldots$ & 192.870 & 622.857 & 74.646 & 890.373 \\
\hline $1843 \ldots \ldots \ldots \ldots$ & 223.867 & 761.879 & 386.387 & 1.372 .133 \\
\hline 1844 & 232.867 & 852.281 & 0 & 1.085 .148 \\
\hline 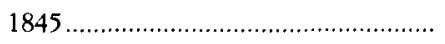 & 188.397 & 519.176 & 4.649 & 712.222 \\
\hline $1846 \ldots \ldots$ & 30.837 & 4.813 & 548 & 36.198 \\
\hline 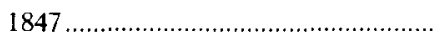 & 103.778 & 66.047 & 96.026 & 265.851 \\
\hline 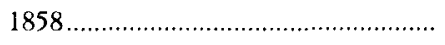 & 213.691 & 532.446 & 182.283 & 928.440 \\
\hline 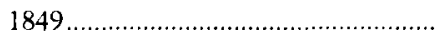 & 276.971 & 946.381 & 414.157 & 1.637 .509 \\
\hline 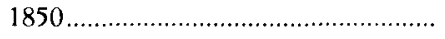 & 359.513 & 1.214 .040 & 408.544 & 1.982 .097 \\
\hline
\end{tabular}

Notas: Sin datos para los años 1791, 1795, 1836, 1837 y 1838.

Datos parciales para los años 1824 y 1825 .

FUENTE: Ver Apéndice.

tafesino secundado por el correntino. Luego, desde 1815 hasta 1830 , fue significativo el aporte de Corrientes, mientras que a partir de la década del 30 los entrerrianos tendrán un peso decisivo en las exportaciones.

Si comparamos la participación del Litoral en el comercio a Buenos Aires con la del Interior vemos que entre 1831 y 1850 las provincias litoraleñas acumulaban un $48 \%$ del total del monto comerciado ${ }^{16}$. Ahora bien, si tenemos en cuenta que

16 Denominamos Interior o provincias interiores a Córdoba, Santiago del Estero, Tucumán, Salta. Jujuy, Catamarca, La Rioja, San Juan, Mendoza y San Luis. 
hemos incluido lo que proviene de una zona vecina pero externa, tal el papel que ya desempeñaba la ex-Banda Oriental, estas cifras podrían ser aún más abultadas ${ }^{17}$. En todo caso, estos valores ilustran con claridad la fuerte dinámica comercial de la región y reflejan la magra contribución del comercio de las provincias interiores.

Con respecto a la composición de las transacciones podemos observar que en el tráfico hubo una constante supremacía de los cueros que representaron el grueso de las mercancías exportadas desde el Litoral. Sin embargo, se debe tener en

\section{CUADRO 2}

Porcentaje del comercio del Litoral sobre el monto total comerciado en Buenos Aires entre 1831 y 1850 (en pesos plata)

\begin{tabular}{|c|c|c|c|}
\hline & Monto comerciado total & Monto Litoral & Porcentaje \\
\hline $1831 \ldots \ldots \ldots \ldots$ & 570.359 & 330.345 & 57,92 \\
\hline $1832 \ldots \ldots \ldots \ldots$ & 1.123 .757 & 368.691 & 32,81 \\
\hline 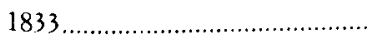 & 817.339 & 343.897 & 42,08 \\
\hline $1834 \ldots \ldots \ldots$ & 994.332 & 493.547 & 49,64 \\
\hline 1835 & 931.404 & 454.121 & 48,76 \\
\hline \multicolumn{4}{|l|}{ 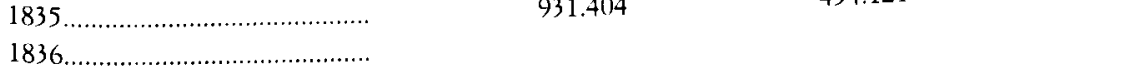 } \\
\hline \multirow{2}{*}{\multicolumn{4}{|c|}{ 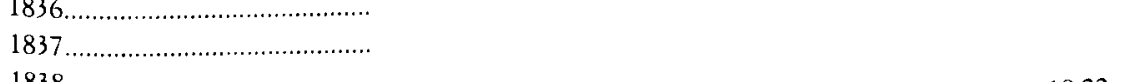 }} \\
\hline 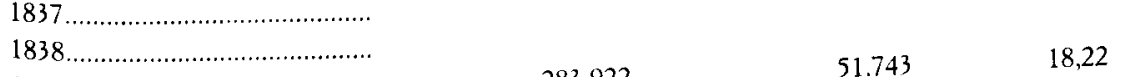 & & & \\
\hline $1839 \ldots \ldots \ldots$ & 283.922 & 51.743 & 18,22 \\
\hline 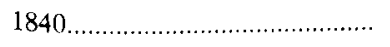 & 211.398 & 25.277 & 19,96 \\
\hline $1841 \ldots \ldots \ldots \ldots$ & 1.597 .214 & 991.895 & 62,10 \\
\hline 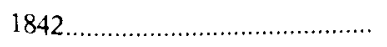 & 1.632 .375 & 890.373 & 54.54 \\
\hline 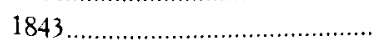 & 3.206 .825 & 1.372 .133 & 42,79 \\
\hline 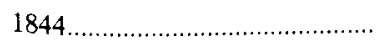 & 2.728 .271 & 1.085 .148 & 39,77 \\
\hline 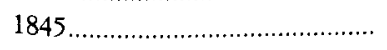 & 1.807 .954 & 712.222 & 39,39 \\
\hline $1846 \ldots \ldots \ldots \ldots \ldots \ldots$ & 264.134 & 36.198 & 13,70 \\
\hline $1847 \ldots \ldots$ & 639.104 & 265.851 & 41,60 \\
\hline 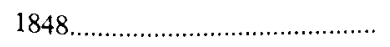 & 1.705 .339 & 928.440 & 54,44 \\
\hline 1849 & 2.869 .603 & 1.637 .509 & 57,06 \\
\hline 1850 & 3.424 .885 & 1.982 .097 & 57,87 \\
\hline & Promedio del & & 48,25 \\
\hline
\end{tabular}

Notas: Sin datos para los años 1836,1837 y 1838

FuENTE: Ver Apéndice.

17 Hemos incluido dentro del comercio a Buenos Aires las exportaciones provenientes de una parte de la zona norte de la campaña bonaerense (la que se recuesta sobre el Paraná, en tomo a los puertos de San Nicolás, Zárate, Baradero y San Pedrol y también unos pocos envíos de la capital y la zona sureña del Paraguay. 
cuenta que en diferentes momentos el tráfico adquirió un carácter más diversificado gracias a la presencia de productos secundarios de la ganadería y de otros que tenían como destino los mercados domésticos.

\section{GRÁFICO II}

Composición del comercio Litoral-Buenos Aires, 1783-1850

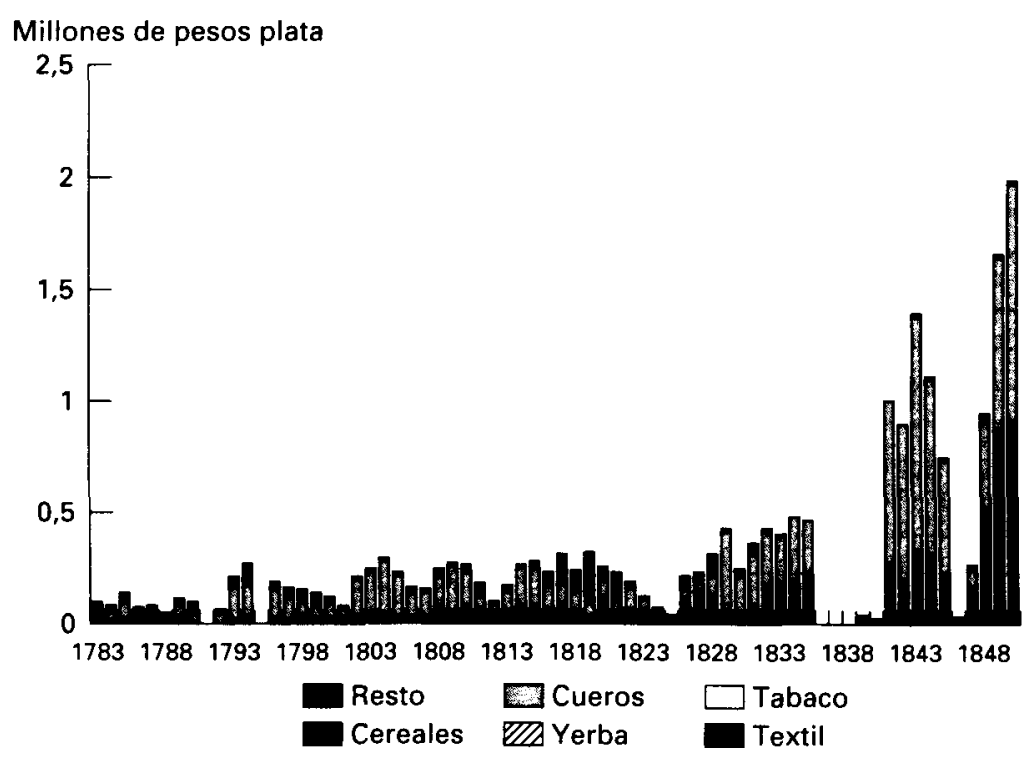

Así, desde 1783 hasta 1815 los cueros representaron un $57 \%$ de los valores, mientras que la yerba mate alcanzó un $17 \%$, los textiles el $8 \%$ y un resto del $18 \%$. Más tarde, entre 1816 y 1825 , cae la presencia de los cueros al $38 \%$, en tanto que el tabaco llega al $32 \%$, la yerba mate al $16 \%$ y un resto de $14 \%$. Para el período 1826 a 1850 los cueros representan el $58 \%$, seguido por los productos secundarios de la ganadería (lana, tasajo y suelas), $6 \%$, y un resto de $36 \%$.

Como vimos, a pesar de la importancia que tuvieron los cueros en este comercio, no es despreciable el aporte relativo de otros efectos los cuales no han sido siempre ponderados por los estudios sobre el tema. Así, si medimos el porcentaje de incidencia de los cueros sobre el total tomando dos grandes momentos, vemos que durante el período colonial los cueros alcanzaron el $60,53 \%$, mientras que en el periodo independiente llegaron a representar el $54,57 \%$ de los valores comerciales. Por tanto, el predominio de los cueros fue real, pero siempre estuvieron acompañados por otros productos que incidían fuertemente en la composición del tráfico. 


\section{CUADRO 3}

Valor y porcentaje de los cueros exportados desde el Litoral sobre el monto total del comercio litoraleño a Buenos Aires entre 1783 y 1850 (en pesos plata)

\begin{tabular}{|c|c|c|c|}
\hline & Monto del Litoral & Monto de los cueros & Porcentaje \\
\hline $1783 \ldots$ & 97.354 & 11.391 & 11,70 \\
\hline 1784 & 89.857 & 34.183 & 38,04 \\
\hline $1785 \ldots \ldots \ldots$ & 135.311 & 70.524 & 52,12 \\
\hline 1786 & 83.548 & 46.704 & 55,90 \\
\hline 1787 & 83.284 & 41.817 & 50,21 \\
\hline 1788 & 42.807 & 15.879 & 37,09 \\
\hline 1789 & 124.787 & 52.310 & 41,92 \\
\hline 1790 & 98.454 & 51.572 & 52,38 \\
\hline 1791 & & & \\
\hline 1792 & 76.332 & 52.064 & 68,21 \\
\hline $1793 \ldots \ldots \ldots \ldots \ldots \ldots \ldots \ldots$ & 207.307 & 140.928 & 67,98 \\
\hline 1794 & 254.899 & 139.870 & 54,87 \\
\hline $1795 \ldots \ldots \ldots \ldots \ldots$ & & & \\
\hline $1796 \ldots \ldots \ldots \ldots \ldots \ldots$ & 207.747 & 146.437 & 70,49 \\
\hline 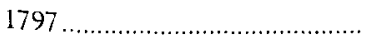 & 154.065 & 92.641 & 60,13 \\
\hline 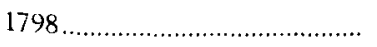 & 172.478 & 63.672 & 36,92 \\
\hline 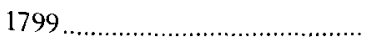 & 179.551 & 53.640 & 29,87 \\
\hline 1800 & 120.561 & 65.333 & 54,19 \\
\hline 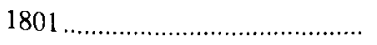 & 104.258 & 48.918 & 46,92 \\
\hline 1802 & 220.633 & 165.645 & 75,08 \\
\hline 1803 & 241.170 & 188.750 & 78,26 \\
\hline 1804 & 304.791 & 223.316 & 73,27 \\
\hline 1805 & 249.014 & 181.758 & 72,99 \\
\hline 1806 & 176.163 & 118.998 & 67,55 \\
\hline $1807 \ldots \ldots \ldots$ & 157.636 & 127.537 & 80,91 \\
\hline 1808 & 232.198 & 129.906 & 55,95 \\
\hline 1809 & 282.491 & 208.327 & 73.75 \\
\hline 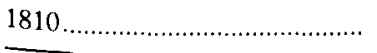 & 252.032 & 160.255 & 63,59 \\
\hline \multicolumn{3}{|c|}{ Promedio del periodo colonial } & 60,53 \\
\hline $1811 \ldots$ & 166.520 & 63.086 & 37,88 \\
\hline 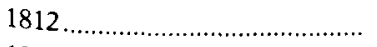 & 216.888 & 27.037 & 12,47 \\
\hline 1813 & 397.546 & 97.438 & 24,51 \\
\hline 1814 & 480.868 & 171.512 & 35,67 \\
\hline 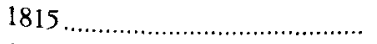 & 329.151 & 174.860 & 53,12 \\
\hline 1816 & 297.576 & 102.350 & 34,39 \\
\hline 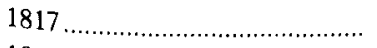 & 237.201 & 116.821 & 49,25 \\
\hline 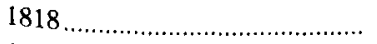 & 167.163 & 87.192 & 52,16 \\
\hline $1819, \ldots \ldots \ldots \ldots \ldots \ldots \ldots$ & 127.814 & 67.601 & 52,89 \\
\hline $1820 \ldots \ldots \ldots \ldots \ldots \ldots \ldots \ldots \ldots \ldots \ldots \ldots \ldots \ldots$ & 311.609 & 66.796 & 21,44 \\
\hline
\end{tabular}




\section{CUADRO 3 (continuación)}

\begin{tabular}{|c|c|c|c|}
\hline & Monto del Litoral & Monto de los cueros & Porcentaje \\
\hline $1821 \ldots$. & 199.077 & 70.335 & 35,33 \\
\hline $1822 \ldots$ & 221.120 & 99.178 & 44,85 \\
\hline 1823 & 126.087 & 45.256 & 35,89 \\
\hline 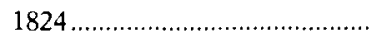 & 71.390 & 18.372 & 25,73 \\
\hline 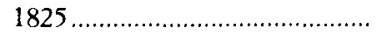 & 40.610 & 18.060 & 44,47 \\
\hline 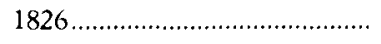 & 184.061 & 40.850 & 22,19 \\
\hline 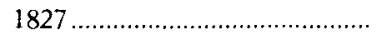 & 208.343 & 50.228 & 24,11 \\
\hline 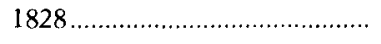 & 222.326 & 77.591 & 34,90 \\
\hline 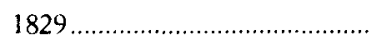 & 421.007 & 338.831 & 80,48 \\
\hline 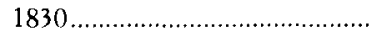 & 264.802 & 172.571 & 65,17 \\
\hline $1831 \ldots \ldots \ldots \ldots \ldots \ldots$ & 330.345 & 225.381 & 68,23 \\
\hline 1832. & 368.691 & 244.531 & 66,32 \\
\hline 1833 & 343.897 & 206.834 & 60,14 \\
\hline 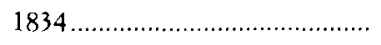 & 493.547 & 284.248 & 57,59 \\
\hline 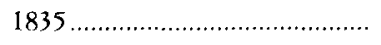 & 454.121 & 214.318 & 47,19 \\
\hline 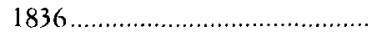 & & & \\
\hline 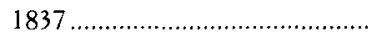 & & & \\
\hline 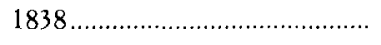 & & & \\
\hline 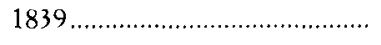 & 51.743 & 22.385 & 43,26 \\
\hline 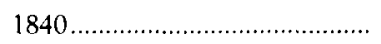 & 25.277 & 4.429 & 17,52 \\
\hline 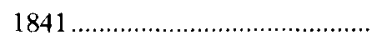 & 991.895 & 728.414 & 73,44 \\
\hline 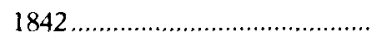 & 890.373 & 692.894 & 77,82 \\
\hline $1843 \ldots \ldots \ldots \ldots \ldots \ldots \ldots$ & 1.372 .133 & 1.025 .488 & 74,74 \\
\hline 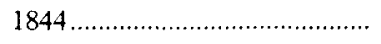 & 1.085 .148 & 765.487 & 70,54 \\
\hline 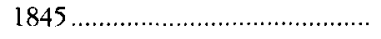 & 712.222 & 462.207 & 64,90 \\
\hline 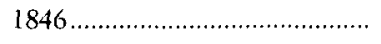 & 36.198 & 9.826 & 27,14 \\
\hline $1847 \ldots \ldots \ldots \ldots \ldots \ldots$ & 265.851 & 86.599 & 32,57 \\
\hline 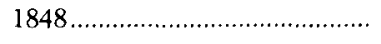 & 928.440 & 388.639 & 41,86 \\
\hline 1849 & 1.637 .509 & 755.329 & 46,13 \\
\hline 1850 & 1.982 .097 & 1.068 .247 & 53,89 \\
\hline \multicolumn{3}{|c|}{ Promedio del periodo colonial } & 54,57 \\
\hline \multicolumn{3}{|c|}{ PROMEDIO TOTAL } & 55,80 \\
\hline
\end{tabular}

Notas: Sin datos para los años $1791,1795,1836,1837$ y 1838.

FuENTE: Ver Apéndice.

Por su parte, las cifras de las exportaciones ultramarinas del puerto de Buenos Aires que brinda Woodbine Parish nos permite hacer una estimación de la incidencia que tuvieron los cueros vacunos y baguales litoraleños en las mismas. Así, para 1849 y 1850 , el Litoral aporta el 15,07 y el $22,02 \%$ de cueros vacunos, respectivamente, y el 38,38 y el $28,71 \%$ de cueros baguales, también respectiva- 
mente. En cuanto a la composición de las exportaciones, el lapso 1820-1830 fue el período en el cual la diversificación fue mayor, adquiriendo importancia el tabaco, la cal y los productos secundarios de la ganadería, tales como las suelas, la lana y el tasajo, los que, desde la década de 1830 en adelante, siguieron teniendo un peso destacado.

\section{CUADRO 4}

Cantidad de cueros llegados a Buenos Aires desde cada provincia del Litoral argentino, 1849-1850

\begin{tabular}{|c|c|c|c|c|}
\hline \multicolumn{5}{|c|}{ CUEROS VACUNOS } \\
\hline & Santa $F e$ & Corrientes & Entre Rios & Total \\
\hline 1849 & 48.956 & 131.345 & 266.056 & 446.357 \\
\hline 1850 & 58.358 & 105.478 & 369.887 & 533.723 \\
\hline
\end{tabular}

* Incluye cueros vacunos secos y salados.

\begin{tabular}{|c|c|c|c|c|}
\hline \multicolumn{5}{|c|}{ CUEROS BAGUALES } \\
\hline & Santa Fe & Corrientes & Entre Rios & Total \\
\hline 1849 & 1.466 & 25.531 & 64.539 & 91.536 \\
\hline 1850 & 34 & 11.407 & 42.285 & 53.726 \\
\hline
\end{tabular}

* Incluye cueros baguales secos y salados.

Exportación de cueros a través del puerto de Buenos Aires.

El Litoral frente a la campaña bonaerense y al interior, 1849-1850

\begin{tabular}{|c|c|c|c|c|c|c|c|}
\hline \multicolumn{8}{|c|}{ CUEROS VACUNOS } \\
\hline & Exportación & Litoral & $\%$ & Interior & $\%$ & $B S . A S$. & $\%$ \\
\hline $1849 \ldots \ldots \ldots \ldots \ldots \ldots \ldots \ldots$ & 2.961 .342 & 446.357 & 15,07 & 325.939 & 11,01 & 2.189 .046 & 73,92 \\
\hline $1850 \ldots \ldots \ldots \ldots \ldots \ldots \ldots \ldots \ldots \ldots \ldots$ & 2.424 .251 & 533.723 & 22,02 & 335.564 & 13,84 & 1.554 .964 & 64,14 \\
\hline
\end{tabular}

\begin{tabular}{cccccccc}
\hline \multicolumn{10}{c}{ CUEROS BAGUALES } \\
\hline & Exportación & Litoral & $\%$ & Interior & $\%$ & BS. AS. & $\%$ \\
\hline $1849 \ldots \ldots \ldots \ldots \ldots \ldots \ldots . .$. & 238.514 & 91.536 & 38,38 & 79.222 & 33,21 & 67.756 & 28,41 \\
$1850 \ldots \ldots \ldots \ldots \ldots \ldots \ldots \ldots . .$. & 187.107 & 53.726 & 28,71 & 59.678 & 31,90 & 73.703 & 39,39 \\
\hline
\end{tabular}

FuENTES: Cifras de exportación: Parish (1958), p. 512.

Cifras del Interior: Rosal (1994), pp. 12-13. 


\section{EL COMERCIO DE LAS PROVINCIAS}

\subsection{El comercio de Corrientes}

El comportamiento del comercio correntino sufrió una sucesión de movimientos de alzas y bajas. Desde 1783 hasta por lo menos 1811 este tráfico muestra un periodo de alza. Posteriormente, se hacen sentir las consecuencias de las luchas de independencia provocando una serie de años de bajas entre 1812-1815 y 1819 . 1825. A partir de 1826 comienza una etapa de ascenso que llegará hasta fines de la década de 1830. Por último, hacia finales del periodo estudiado hay una gran variabilidad en los montos, producto de la situación político-económica de la provincia, de la competencia de los efectos paraguayo-brasileros, a las que se agrega el efecto negativo de los bloqueos comerciales que sufrió el puerto de Buenos Aires.

\section{GRÁFICO III}

Composición del comercio Corrientes-Buenos Aires, 1783-1850

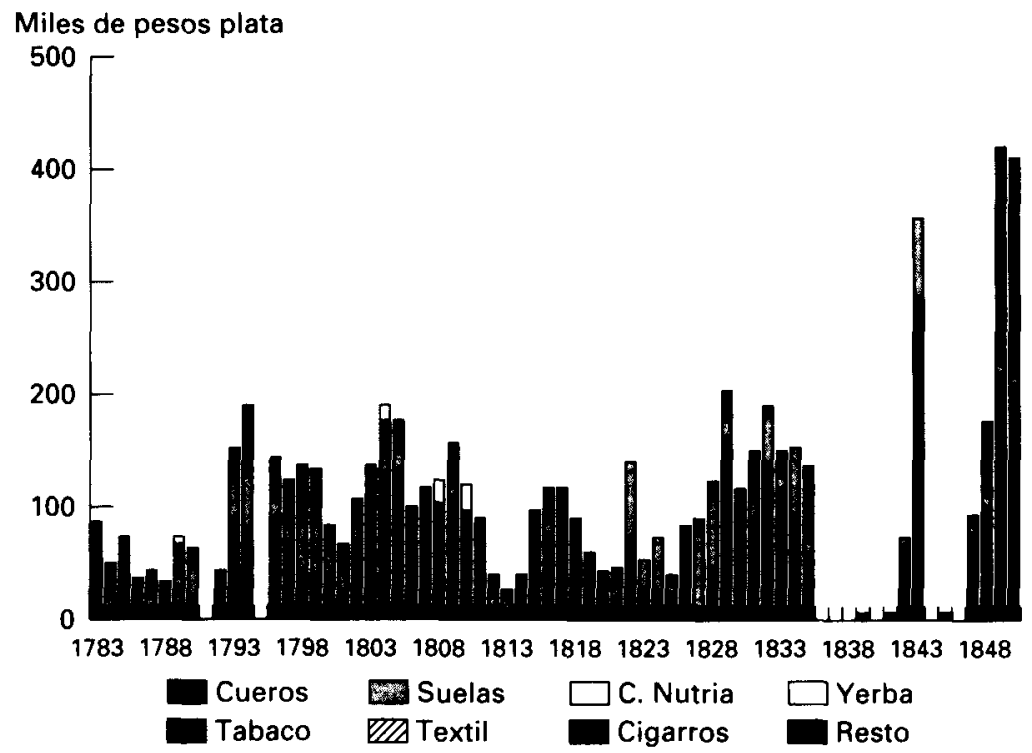

En cuanto a la composición del comercio durante el período colonial notamos la presencia de tres efectos principales: la yerba mate, los textiles y los cueros. Estos últimos a partir de 1790 adquieren mayor peso en la comercialización, llegando a representar, junto a los restantes productos pecuarios, cerca del $90 \%$ de los valo- 
res mercantiles. Ya partir de 1810-20 desaparecen los textiles y disminuye la presencia de la yerba mate, debido esencialmente a la pérdida del control político-económico de las ex misiones por parte de los comerciantes correntinos. Paralelamente, cobra importancia el comercio de tabaco acompañado por los cigarros, mientras que se mantiene la supremacía de los productos ganaderos (cueros y suelas). También, desde mediados de los años de 1820 se consolida en Corrientes un avance de la producción ganadera en el sur de la provincia. Este proceso implica un aumento de los stock ganaderos y de las tierras de pastoreo disponibles que posibilitará un fuerte crecimiento en la exportación de cueros y de suelas, situación de bonanza que se experimentará hasta fines de la década de 1830. Durante aquella década también declina considerablemente el comercio de yerba mate y en menor medida el de tabaco, que ya no encontrarán un mercado disponible en Buenos Aires y serán desplazados por producciones paraguayas-brasileñas. Las posibilidades del tabaco en el mercado porteño fueron limitadas, su producción y comercialización continuó siendo periférica respecto de la paraguaya. No obstante lo señalado, los índices del comercio de tabaco correntino a Buenos Aires indican que sus volúmenes no fueron despreciables. Pero ello no presentaba una situación como la considerada por Thomas Whighan, el cual afirma que «entre 1820 y 1850 , la historia del tabaco correntino tenía proyecciones optimistas pero éstas fueron destruidas por las realidades políticas ${ }^{18}$.

Por su parte, la yerba mate de origen brasileño ya desde la década de 1810 había comenzado a desplazar a la correntina y paraguaya de la plaza porteña ${ }^{19}$. Esta alteración se habría dado, como bien señala $\mathrm{T}$. Whighan, debido a que «los precios altos estimularon directamente la expansión de las economías con base en la yerba mate en áreas que hasta entonces no la habían producido para su exportación» ${ }^{20}$, de este modo «el interior de la Provincia de Paraná y varios distritos de Río Grande do Sul se beneficiaron enormemente» ${ }^{21}$.

No obstante lo señalado, debemos tener en cuenta que ese efecto sustitutivo no se dio plenamente hasta bien entrada la década de 1830 , ya que el conflicto bélico con los portugueses (1826-28) afectó este comercio, provocando un gran alza en sus precios. Esta coyuntura habría alterado la demanda de yerba correntina, la que pudo reemplazar en parte a la brasileña, registrando un crecimiento en su tráfico y una baja en su precio. Además, también se dio un circunstancial aumento de la oferta de yerba correntina, ya que éstos habian organizado, desde 1827, incursiones

${ }^{18}$ Whighan (1986), p. 248. (1985)

Sobre la situación de la yerba mate en Buenos Aires, puede verse también el trabajo de Bilbao

${ }^{20}$ Whighan (1986) p. 248.

${ }^{21}$ Whighan (1986), p. 196. 
sobre los territorios de las Misiones. El avance sobre los yerbatales paraguayos parece haber permitido a los correntinos apropiarse de parte de la producción. Éstos, desde 1828, comenzaron a introducir yerba paraguaya a Buenos Aires, llegando a completar entre $1829-31$ el $30 \%$ de sus exportaciones con producción de aquel origen.

Pero, a principios de 1830, el conflicto correntino-paraguayo se agravó. La apetencia tenaz de ambos estados por las Misiones —zona estratégica para la producción yerbatera, además de territorio clave como ruta comercial de las exportaciones del Paraguay - tornó sumamente inestable la presencia correntina en aquella región ${ }^{22}$.

Por tanto, la suerte de la yerba mate de Corrientes estuvo ligada a las condiciones adversas que tuvo que enfrentar en el mercado; ya en 1831 los valores de la de Río Grande y Paranaguá recuperaron sus precios habituales muy por debajo del que registraba aquélla. Así, si comparamos los precios y además tomamos en cuenta el peso de los aranceles con que ingresaban al mercado porteño la yerba correntina y las de Paranaguá y Río Grande se hacen evidentes las ventajas que tuvieron estas últimas. Como dijimos, salvo los años de la guerra con los portugueses el precio de la yerba brasileña fue siempre inferior al de la correntina, por lo cual los costos impositivos al ser de carácter ad valórem también favorecieron a las mercancías del Brasil.

Entonces, según nuestros datos, el precio de la yerba «del país» no fue inferior al de la extranjera; y tampoco recibió a través de los aranceles una protección que le permitiera una situación de preferencia ${ }^{23}$. En cambio, si vemos el caso del tabaco, la incidencia de los precios y el monto del arancel muestra que efectivamente se recargó más al proveniente del Brasil. De esta manera, para los dos productos analizados no acordamos completamente con lo afirmado por Burgin cuando señala que en Buenos Aires «recibían tratamiento de preferencia el tabaco y la yerba mate del país» ${ }^{24}$.

Por lo expuesto, creemos que si bien para algunos productos podria ser cierto que «los precios locales subían más lentamente que los internacionales, ...[y por tanto] se ensanchó la separación existente entre los precios locales e internacionales, ...[otorgando] un efecto protector de la industria local" ${ }^{25}$, eso no ocurrió con la yerba mate, por lo cual esta hipótesis debe ser estudiada y demostrada para cada

22 Esa zona fue estratégica como ruta comercial de los productos paraguayos, que a través de San Borja e Itapúa eran introducidos y exportados por los comerciantes brasileños. Véase Areces y Bouvet (1987).

${ }^{23}$ Ver Bilbao (1985).

${ }^{24}$ Burgin (1960), p. 107.

29 Burgin (1960), p. 110. 
uno de los productos de gran consumo en el Río de la Plata. Por tanto, las mercancías correntinas dirigidas al mercado doméstico marcan, a partir de sus fluctuaciones en el comercio conjuntamente con la caída de sus precios, la dificultad que enfrentaron en Buenos Aires para competir con los productos paraguayos-brasileños, que parecen haberle impedido mantenerse en esa plaza. De esta manera la economía correntina que fue la que, después de la independencia, más tempranamente creció parecería haber encontrado un límite a su expansión hacia principios de la década de 1840 .

\subsection{El comercio de Entre Rios}

El ritmo del comercio de Entre Ríos registra cifras bajas entre 1783 y finales de la década de 1820 mostrando una cierta continuidad en el desempeño de las exportaciones. De esta manera, nuestro análisis difiere de lo sostenido, entre otros, por César Pérez Colman, quien afirma que la situación propicia que se había experimentado a principios del siglo XIX fue afectada severamente por las guerras de la independencia y las civiles, las cuales habrían dañado a numerosas industrias $y$ al comercio local generando a partir de alli una coyuntura de crisis ${ }^{26}$. Una visión similar en cuanto al estado de desamparo del comercio es sostenida por Beatriz Bosch para quien la situación llegó a ser sumamente crítica, al punto de que a principios de 1820 se daba una escasez de artículos de primera necesidad ${ }^{27}$.

A través de nuestros datos se observa que será recién a partir de 1830 que Entre Ríos experimentará un significativo crecimiento en las exportaciones producto del considerable aporte de la expansión productiva de la zona oriental de la provincia. De esta manera podemos afirmar que en el comercio se diferencian dos etapas en la evolución de la economía entrerriana, una que llega hasta fines de la década de 1820, circunscripta a la costa del Paraná, y otra posterior que tiene como eje a la costa del Uruguay. Así, debido al crecimiento de esta nueva zona las exportaciones entrerrianas llegarán a representar el 30\% del total de los valores comerciados en la plaza de Buenos Aires entre 1831-1850.

La composición del comercio entrerriano indica una clara supremacía de los cueros vacunos durante el período estudiado. De todos modos, la exportación de cal tuvo cierta importancia, sobre todo a partir de la década de 1820. Más tarde, hacia el final del período analizado, adquieren importancia los productos secundarios de la ganadería, en especial la lana, el sebo y el tasajo.

\footnotetext{
26. Pérez Colman (1937), pp. 35-54, y (1946), pp. 217-225.

27 Bosch (1978), pp. 87-88.
} 


\section{GRÁFICO IV}

\section{Composición del comercio Entre Rios-Buenos Aires, 1783-1850}

Miles de pesos plata

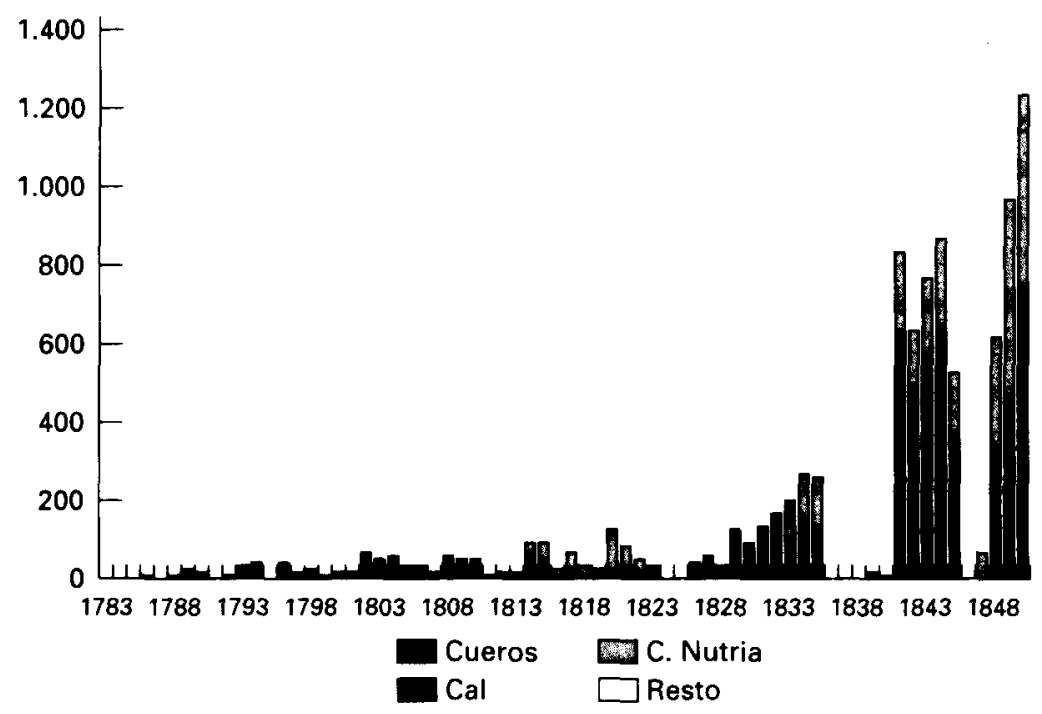

En cuanto a la producción ganadera, ésta estuvo concentrada desde fines del siglo XVIII en la Bajada del Paraná, aunque en esos años no experimentó un desarrollo demasiado significativo. Más tarde, la situación parece haber empeorado con los sucesos revolucionarios, pero ya en los primeros años del decenio de $1820 \mathrm{el}$ gobierno provincial intentaba estimular a los productores ganaderos en pos de lograr una recuperación de los bienes pecuarios; así buscaba «los medios de hacer reembolsar a los hacendados que han sido arruinados en el curso de la guerra civil» ${ }^{28}$, para lo cual decretaba que los afectados se consideraran con derecho de recibir algún resarcimiento por los daños causados.

Los valores comerciados a partir de la década de 1830 muestran que la zona del Paraná aumentó lentamente sus exportaciones, mientras que la zona sobre la costa del Uruguay fue la que logró una mayor dinámica en la producción pecuaria. En este último caso fue clave la expansión de la frontera productiva sobre tierras vacantes del este de la provincia, proceso que comenzó en los años '20 y que incluso permitió a los estancieros obtener ganado en la costa de enfrente; así los

2* Recopilación de leyes, decretos y acuerdos de la Provincia de Entre Ríos, I. Concepción del Uruguay (1875). Pág. 391. 
productores «que pasen a la Banda Oriental caballadas, y traigan en su retorno ganados, quedan absolutamente libres..» sin tener que pagar ningún derecho ${ }^{29}$. De este modo se obtendrían tierras y ganado, los dos factores básicos para el futuro crecimiento de las actividades pecuarias.

Finalmente, durante el decenio de 1840 el eje del comercio provincial se trasladó definitivamente a la costa occidental del río Uruguay. En esos años se producirá un boom de los bienes pecuarios, dentro de los cuales ocupan un lugar importante el sebo, la grasa y el tasajo ${ }^{30}$.

La producción de cal se desarrolló también desde fines del siglo XVIII. Ya para 1809 había once establecimientos que estaban afincados en ambas riberas de Entre Ríos. Uno de los primeros en explotar los yacimientos habría sido el conocido empresario Manuel Barquín, a quien en años posteriores le siguieron una serie de productores y arrendatarios entre los que estuvieron Juan de Iriarte, José Díaz Velez, Salvador Espeleta, Juan Garrigos, Francisco Candiotti, Camilo Idoate, todos ellos importantes personajes de la economía entrerriana. Ya en la era independiente, el Estado provincial fue también uno de los impulsores de esta producción, no sólo como arrendatario sino también como productor en varios yacimientos ${ }^{31}$. Un claro ejemplo de esta actividad se puede ver en 1822 cuando el gobierno mandó a que «en el horno que se conoce de la propiedad de Don José Eusebio Ereñu, se deben construir por cuenta del Estado 6000 fanegas de cal...» ${ }^{32}$. Esta producción fue parte significativa de las exportaciones de la provincia, llegando en algunos casos a enviarse en parte de pago por las deudas contraidas por el estado de Entre Ríos con el de Buenos Aires. Así en los decenios de 1820-30, la cal se transformó en un producto muy demandado ya que no sólo se usaba como un bien esencial en la construcción, sino que también era fundamental para el curtido de cueros. Como señalamos, esta mercancía fue, después de los efectos pecuarios, el principal producto en importancia en la economía entrerriana. Su exportación, a pesar de algunos altibajos, tuvo una media de 6.000 fanegas, y su producción estuvo centrada en la costa del Paraná. De esta forma, Entre Ríos, que tuvo un magro aporte a fines del siglo XVIII y en las primeras dos décadas del XIX, será de las tres provincias estudiadas, la que finalmente logró un mayor crecimiento de sus exportaciones, gracias, fundamentalmente, a la expansión de la producción pecuaria destinada al mercado atlántico.

${ }^{29}$ Recopilación de lcyes, decretos y acuerdos de la Provincia de Entre Rios, decreto del 30/11/1823. I.

31) Urquiza Almandoz (1978), pp. 172-187.

${ }^{3}$ Según el decreto del 3/6/1822, el Estado arrienda por su cuenta la calera que perteneciera a Doña Juana Argerich por 30 pesos mensuales. Recopilación de leyes, decretos y acuerdos de la Provincia de Entre Rios, I.

${ }^{32}$ Recopilación de leyes, decretos y acuerdos de la Provincia de Entre Rios, I. 


\subsection{El comercio de Santa Fe}

El comercio de Santa Fe manifiesta una limitada expansión hasta 1810. Posteriormente, gracias a su rol de reexportador de productos paraguayo-correntinos, tiene un alza muy importante que llega hasta 1816, con un máximo en 1813-1814, en que su tráfico está compuesta por grandes cantidades de yerba mate y tabaco. A pesar de que - como señalamos- entre 1810 y 1815 las exportaciones santafesinas aumentaron notablemente, el comercio de productos pecuarios decayó, por lo que Santa Fe parecería haber sido la más perjudicada de las provincias del Litoral por las guerras de independencia y civiles, al tiempo que se muestra como la provincia litoraleña que tuvo menor capacidad de expandir su frontera productiva ganadera. Como han indicado Manuel Cervera y Horacio Pereyra, la campaña de la provincia desde la década de 1810 se encontraba escasa de ganado a consecuencia de los saqueos, lo que habría llevado incluso a interrumpir el tráfico ${ }^{33}$.

\section{GRÁFICO V}

Composición del comercio Corrientes-Buenos Aires, 1783-1850

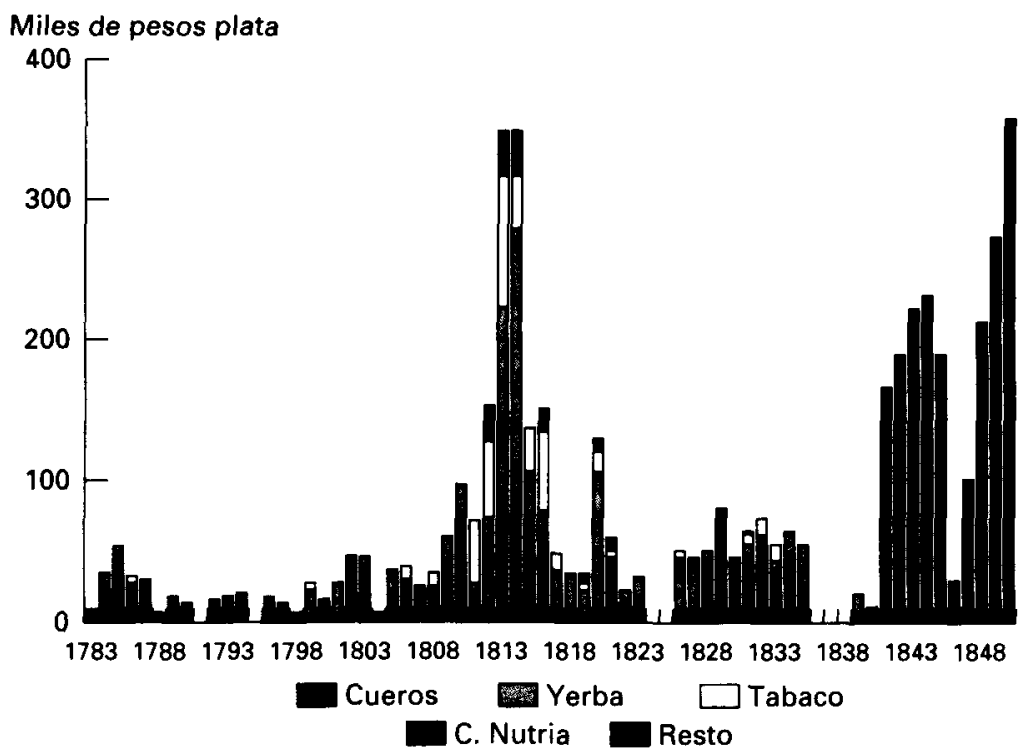

${ }^{33}$ Cervera (1907), pp. 905-970, y Pereyra (1960), pp.123-159. 
No obstante lo expuesto, la situación del comercio no fue tan crítica a largo plazo, así en las décadas de 1820 y 1830 sus valores se estancan y a partir de 1840 comenzará una etapa de crecimiento. El comercio santafesino estuvo conformado esencialmente por cueros vacunos, pero en diversos momentos se complementó con otros productos. Así, como indicamos, entre 1814 a 1821 el $69 \%$ del valor corresponde a yerba mate y tabaco. Luego a partir de la década de 1820 hasta fin del período estudiado, también tuvieron incidencia los cueros de nutria, las maderas y los cereales.

Los cueros de nutria tuvieron una demanda sostenida en Buenos Aires, ya que era un insumo en la industria de sombreros y también se exportaba exitosamente a ultramar. El comportamiento de este producto en el comercio fue muy fluctuante; tuvo un máximo durante los años 1826-27 llegando a enviarse 11.000 docenas, para luego descender y tener grandes oscilaciones. La caza de estos animales, a veces indiscriminada, a lo que se sumaron sequías, parece haber dificultado mantener un comercio estable de cueros. Por lo que, a pesar de una demanda sostenida, no hubo una respuesta acorde de la oferta del producto, ni aun luego del aumento de precios que este proceso generó.

Por su parte, la proximidad con los bosques del Chaco permitió a los santafesinos realizar una importante explotación forestal. Así, éstos exportaban camas, rayos, mazas, ejes, tirantes y palos largos que se utilizaron en la construcción de carretas, que eran los vehículos de transporte por excelencia de esta época. También enviaban un importante número de tablas, postes y palos que se usaban en la construcción y en las actividades rurales. De esta forma, la demanda de estos bienes fundamentales para la vida económica posibilitó a los santafesinos mantener, sobre todo en las últimas tres décadas estudiadas, un constante tráfico de diversos tipos de maderas.

Las exportaciones santafesinas, que sufrieron altibajos debido al inestable rol de puerto reexportador y su posterior estancamiento productivo, se consolidarían recién luego de 1840 cuando se inicia una etapa de lento crecimiento en su economía que lo lleva a aportar el $10 \%$ del total de los valores comerciados en Buenos Aires.

\section{CONCLUSIONES}

La región rioplatense logró un crecimiento económico que se inició a fines del siglo XVIII y que se aceleró durante el periodo independiente -pese a los conflictos bélicos- como consecuencia de la estrecha vinculación con los mercados externos en función de la creciente demanda de productos pecuarios. 
El comercio exterior de la región litoraleña marca las siguientes etapas de evolución: desde 1783 las exportaciones, aun con altibajos, muestran un alza sostenida hasta 1815 . Luego el tráfico sufre una merma hasta 1825 , en que comienza un nuevo lapso de crecimiento. Así, a pesar de algunos años de baja, el período posrevolucionario no se puede considerar como una etapa crítica. Por tanto, sostenemos que las exportaciones, aunque tuvieron algunas oscilaciones, crecieron después de la independencia más rápidamente que durante el período colonial, y por tanto también el conjunto de la economía litoraleña, si bien constatamos que el aporte de cada provincia en el total del comercio tuvo una dinámica diferente de crecimiento.

Dentro de las etapas señaladas notamos que durante la colonia y a principios de la era independiente el eje comercial litoraleño estuvo hegemonizado sobre el río Paraná; más tarde, en la década de 1830, aquél se trasladaría hacia el río Uruguay debido a la expansión de las fronteras productivas, convirtiéndose así la franja ribereña sobre el mismo en el principal núcleo de la producción y el comercio en el Litoral.

En cuanto a la composición de las exportaciones hubo algunas variaciones a lo largo de los 68 años analizados, si bien los cueros fueron siempre hegemónicos. Incluso en el peor momento (1815-1825) significaron cerca del $40 \%$ del total del monto, superando el $50 \%$ del valor comercial antes y después de aquél. Durante los últimos 25 años el tráfico se complementó con los productos secundarios de la ganadería (lana, tasajo y suelas), lo que acentuó el perfil pecuario del mismo. Esto comprueba que la mayor parte de las producciones litoraleñas se dirigieron hacia el mercado ultramarino.

Respecto a los bienes destinados al mercado doméstico, no fueron despreciables, pero su situación luego de la revolución no fue tan ventajosa. Así, productos como la yerba mate, los textiles y en menor medida el tabaco - que durante el período colonial habían tenido un mercado seguro en Buenos Aires- sufrirán, sobre todo a partir de la década de 1820 , la competencia de los productos paraguayosbrasileños que finalmente los desplazarán del mercado.

De esta manera, el Litoral argentino - a diferencia de otras regiones hispanoamericanas- experimentó una transición económica relativamente exitosa entre el período colonial y la etapa independiente. Esta situación posibilitó que tempranamente se consolidara la expansión de las fronteras productivas, cuyos bienes se volcaron hacia el mercado exterior adquiriendo una dinámica creciente a lo largo de todo el siglo XIX.

\section{APÉNDICE SOBRE FUENTES}

En este trabajo utilizamos los datos de Claudia Wentzel sobre el comercio del Litoral entre 1783 y 1821, extraídos de la serie de las Guias de comercio y los 
Libros de Alcabalas de Buenos Aires conservados en el Archivo General de la Nación ${ }^{34}$. Para los años subsiguientes se han consultado esencialmente cuatro tipos de fuentes. En primer término para el período de 1822 a 1833 hemos tomado la información de los Manifiestos de Aduana, documento que presentaban los consignatarios de mercancías ante la aduana de Buenos Aires para retirar sus productos del puerto ${ }^{35}$. Esta fuente indica: la fecha de arribo y el nombre de la embarcación; los efectos introducidos, así como su procedencia y volumen (expresados en arrobas, libras o unidades); los precios de aforo y el valor total de la operación. Finalmente señala el o los impuestos que pagaba cada producto, su porcentaje y valor total, el nombre del consignatario y eventualmente el del remitente ${ }^{36}$.

Debido a que una cantidad significativa de efectos introducidos en Buenos Aires no abonaban impuesto de entrada - especialmente los productos ganaderos y las maderas-, éstos solían no ser declarados en los manifiestos, por lo que esta omisión impide la reconstrucción de una parte del tráfico. Pero dicho problema ha podido ser salvado al complementarse los documentos anteriores con la serie de Libros de Casilla de Resguardo de Aduana de Buenos Aires entre 1822-33; éstos son anuales, están rubricados y registraban diariamente la entrada de todas las mercancías a la casilla de la aduana. En esta última fuente se indica: fecha de arribo y nombre del barco, tipo y volumen de los productos y el nombre del consignatario ${ }^{37}$.

Por su parte, para el lapso que va desde 1831 a 1835 utilizamos los datos de los libros de Contribución Directa. Éstos son similares a los Manifiestos de Aduana, en donde esencialmente se tomaba nota del impuesto de Contribución Directa que gravaba el cuatro por mil del valor de la operación ${ }^{38}$. Finalmente, entre 1839 y 1850 recurrimos a los legajos de la Receptoría General. Cargo y Data, Sección

34 Archivo General de la Nación (en adelante A.G.N.), Buenos Aires, Aduana de Buenos Aires, Entradas Terrestres, Salas XIII y III Libros de Alcabalas de Buenos Aires, Sala XIII.

${ }^{35}$ A G.N., Sala III: 22-4-7, 22-4-8, 22-6-1, 22-6-2, 22-7-2, 22-8-1, 22-8-14, 22-9-3, 22-9-14, 22-10-5,

23-2-2, 23-3-6, Sala X: 37-1-9, 37-1-10, 37-1-11, 37-1-12

${ }^{36}$ A partir de la década de 1820 se cobraron dos tipos de impuestos de entrada de mercancías. Uno es el llamado impuesto de Entrada, que era de carácter ad valórem, fue permanente a los largo de los años analizados; su monto osciló, según los diferentes efectos, entre el $4 \%, 10 \%$ y $20 \%$, dén Directa que lo estipulado por las leyes de aduana de Buenos Aires. El otro impuín comercial.

gravaba el cuatro por mil sobre el monto de la operación com-2-25, 37-2-23 y 37-2-18.

37 A.G.N., Sala X: 37-1-23, 37-1-27, 37-2-17, 37-2-3, 37-2-25, 37-2-23 $23-3-13,23-3-14,23-4-1,23-$

${ }^{38}$ A.G.N., Sala III: 23-1-9, 23-1-10, 23-2-10, 23-2-11, 2 - Además se han utilizado los siguientes legajos $4-2,23-4-3,23-5-4,23-5-5,23-5-6,23-7-4,23-7-5,23-7-6$. Ad 1835 : 23-7-10, 23-7-11, 23-7-12, 23-8-1, 23-

para completar información sobre el último cuatrimestre de 1835: 23-7-10, 8-6 y 24-1-1. 
«Contribución Directa» los cuales esencialmente consignan la misma información que los libros referidos a este impuesto ${ }^{39}$.

A partir del cruce de las fuentes mencionadas se ha obtenido una serie representativa del comercio del Litoral a Buenos Aires ${ }^{40}$. No obstante, debemos señalar que para el caso de Entre Ríos y Santa Fe las cifras que hemos obtenido para los años de 1823 y 1824 no son confiables, pues creemos que en esos años las fuentes presentan datos incompletos para estas provincias; por lo tanto hemos preferido en este estudio no incluir valores para ese lapso ${ }^{41}$. De la misma forma nos falta la información sobre el último cuatrimestre de $1835^{42}$ y el primero de 1839 , y carecemos de las fuentes para los años que van desde 1836 a 1838.

Por otra parte, dada la frecuente ausencia en las fuentes, de 1822 a 1833, de los precios de los productos ganaderos, éstos han sido tomados de los valores al por mayor del mercado de Buenos Aires, para cada una de nuestras operaciones ${ }^{43}$. Estos precios son equivalentes a los de aforo, ya que según la legislación de aduana de Buenos Aires «los derechos [impositivos] se calculan sobre valores de la plaza por mayor, declarados por los interesados al tiempo de presentar su manifiesto» ${ }^{44}$.

Además, hemos constatado que existe similitud entre los precios de aforo y los de la plaza, por lo cual se pueden utilizar indistintamente; como ya ha manifestado Assadourian, «el uso de estos "precios” fiscales puede ser algo más que una tosca aproximación a la realidad, hasta creemos que para ciertos períodos reflejan con bastante fidelidad las variaciones significativas e incluso los accidentes circunstanciales de los precios del mercado al por menor» ${ }^{45}$.

${ }_{39}$ A.G.N., Sala III: 24-5-1, 24-5-2, 24-5-3, 24-5-4, 24-5-5, 24-5-6, 24-6-1, 24-6-2, 24-6-3, 24-6-4, 24 6-5, 24-7-1, 24-7-2, 24-7-3, 24-7-4, 24-7-5, 24-8-1, 24-8-2, 24-8-3, 24-8-4, 24-8-5, 24-9-1, 24-9-2, 24-9-3, $24-9-4,24-9-5,24-9-6,24-9-7,24-10-1,24-10-2,24-10-3,24-10-4,24-10-5,24-10-6,24-11-1,24-11-2,24-$ $11-3,24-11-4,24-11-5,24-11-6,25-1-1,25-1-2,25-1-3,25-1-4,25-1-5,25-1-6,25-1-7,25-2-1,25-2-2,25$ $2-3,25-2 \cdot 4,25-2-5,25-2-6,25-2-7,25-3-1,25-3-2,25-3-3,25-3-4,25-3-5,25-3-6,25-3-7,25-4-1,25-4-2$, $25-4-3,25-4 \cdot 4,25-4 \cdot 5,25-4-6,25-4-7,25-4-8,25-5-1,25-5-2,25-5-3,25-5-4,25-5-5,25-5-6,25-5-7,25$ 5-8, 25-6-1, 25-6-2, 25-6-3, 25-6-4, 25-6-5, 25-6-6, 25-6-7, 25-7-1, 25-7-2, 25-7-3, 25-7-4, 25-7-5, 25-7-6, $25-7-7,25-8-1,25-8-2,25-8-3,25-8-4,25-8-5,25-8-6,25-9-1,25-9-2,25-9-3,25-9-4,25-9-5,25-9-6,25$ 9-7, 25-10-1, 25-10-2, 25-10-3, 25-10-4, 25-10-5, 25-10-6, 25-10-7, 25-10-8, 25-11-1, 25-11-2, 25-11-3, 25 . $11-4,25-11 \cdot 5,25-11 \cdot 6,25-11-7,26-1-1$ y $26-1-2$.

40 Las cifras definitivas que manejamos en este estudio están compuestas por las sumas de las operaciones registradas, unas 34.127 entre 1822 y 1850 , a partir del cruce de las fuentes mencionadas.

41 Para el caso particular de Corrientes nuestros datos también han sido comparados con la información disponible de los libros de salidas de mercancías del puerto de Corrientes, lo que permitió una nueva confirmación de la representatividad de esta serie.

42 De todos modos tratamos de subsanar el problema consultando algunos legajos complementarios (ver nota 38 ).

${ }^{43}$ Para los productos pecuarios los precios han sido tomados de los precios por mayor de la plaza de Buenos Aires del diario La Gaceta Mercantil.

${ }_{44}$ Ver Registro Oficial de la Provincia de Buenos Aires (Año de 1822), T.I, p. 153.

45 Assadourian (1983 b), p. 314. 
También es de advertir que los valores registrados en los documentos a partir de 1822 están expresados en pesos papel. Como sabemos, esa moneda no es un buen indicador debido al fulminante proceso inflacionario que se desató en Buenos Aires a partir de 1826 , por lo que su uso nos impediría un análisis ajustado, así como la comparación con los valores de otros períodos. Para evitar esos problemas hemos convertido el peso papel a onza de oro y con posterioridad a pesos plata como aparecen en el trabajo ${ }^{46}$.

\section{BIBLIOGRAFÍA}

AmARAL, Samuel (1990): «Comercio libre y economías regionales. San Juan y Mendoza, 1780-1820», en Jahrbuch für Geschichte von Staat, Wirtschaft und Gesellschaft Lateinamerikas, band 27, pp. 1-67.

ARECES, L., y BOUVET, N. (1987): «Itapúa: comercio y frontera en el Paraguay del doctor Francia», Siglo XIX, 2: 4, México, Facultad de Filosofía y Letras, Universidad Autónoma de Nueva León.

Assadoundan, Carlos Sempat (1983 a): El sistema de la economia colonial. El mercado interior. Regiones y espacio económico, México, Nueva Imagen.

- 1983 b): El sector exportador de una economía regional del interior argentino. Córdoba. 1800-1860. Esquema cuantitativo y formas de producción), en ídem: El sistema de la economía colonial.., pp. 307.367.

BeTELL, Leslie (ed.) (1991): Historia de América Latina, tomos 5 y 6, Barcelona, Ed. Crítica.

BILBAO, María (1985): «Evolución de precios de la yerba mate y azúcar en Buenos Aires 1823-1832», Rosario, VII Jornadas de Historia Económica (mimeo).

Bonilla, Heraclio, et alia (1981): La independencia del Perú, Lima, I.E.P.

Bosch, Beatriz (1978): Historia de Entre Rios, Buenos Aires, Ed. Plus Ultra.

BuRgin, Miron (1960): Aspectos económicos del federalismo Argentino, Buenos Aires, Ed. Solar/Hachette.

Cervera, Manuel (1907): Historia de la ciudad y provincia de Santa Fe 1573-1853. t. 2, Santa Fe, Ed. La Unión.

COATSWORTH, John (1990): Los orígenes del atraso, México, Ed. Alianza.

CONTI, Viviana (1989): «Una periferia del espacio mercantil andino: el norte argentino en el siglo XIX», en Avances en Investigación. Antropologia e Historia, pp. 37-62.

- (1992): «Espacios económicos y economías regionales. El caso del norte argentino y su inserción en el área andina en el siglo XIX», en Revista de Historia, : 3, pp. 27-40.

- (1993): «El norte argentino y Atacama: producción y mercados», en Siglo XIX, 2: 14, México, Universidad Autónoma de Nueva León, Instituto «Dr. José María Luis Mora» y Universidad de Veracruz, pp. 7-38.

ChIARAmONTE, José Carlos (1991): Mercaderes del Litoral. Economia y sociedad en la provincia de Corrientes, primera mitad del siglo XIX, México-Buenos Aires, Fondo de Cultura Económica.

46 La cotización de la onza de oro es la de Pedro Agote y puede verse en Burgin (1960), pp. 104 y 220. Con respecto a la paridad entre el oro y la plata hémos tomado la de 17 por 1 tal como se señala en Senillosa (1835), p. 33. 
Garavaglia, Juan Carlos (1983): Mercado interno y economía colonial, México, Ed. Grijalbo.

- (1987): «Crecimiento económico y diferenciaciones regionales en el Río de la Plata a fines del siglo XVIII», en Economía, Sociedad y Regiones, Buenos Aires, Ediciones de la Flor.

GOOTENBERC; Paul (1989): Between silver and guano: commercial policy and the State in pos. tindependence Peru, Princeton, Princeton University Press.

HALPERIN DONGHI, Tulio (1963): «La expansión ganadera en la campaña de Buenos Aires (1810-1852)», Desarrollo Económico, 3: 1-2 (abr-sept.), pp. 57-110. Buenos Aires.

- (1972): Revolución y Guerra. Formación de una élite dirigente en la Argentina criolla, Buenos Aires, Ed. Siglo XXI.

- (1980): De la revolución de independencia a la confederación rosista, Buenos Aires, 4ta. reimpresión, Ed. Paidós.

- (1985): Reforma y disolución de los imperios ibéricos 1750-1850, Madrid, Ed. Alianza.

- (1986): Historia contemporánea de América Latina, Madrid, Ed. Alianza.

LANGER, Erick (1987): «Espacios coloniales y economias nacionales: Bolivia y el norte argentino (1810-1930)», en Siglo XIX, : 4, pp. 135-160.

LANGER, Erick, y CONTI, Viviana (1991): «Circuitos comerciales tradicionales y cambio económico en los Andes centromeridionales (1830-1930)», en Desarrollo Económico, 121, pp. 91-111.

LIEHR, Reinhard (ed.), (1989): América Latina en la época de Simón Bolivar. La formación de las economias regionales y los intereses económicos europeos 1800-1850, Berlín, Colloquium Verlag.

MOUTOUKIAS, Zacarías (1988): Contrabando y control colonial en el siglo XVII, Buenos Aires, Centro Editor de América Latina.

- (1992): «El comercio atlántico de Buenos Aires, 1760-1796: crecimiento y continuidad» (mimeo).

PALOMEQUe, Silvia (1989): «La circulación mercantil en las provincias del Interior, 1800 1810», en Anuario IEHS, : 4, Tandil, UNCPBA, pp. 131-210.

PARISH, Woodbine (1958): Buenos Aires y las provincias del Rio de la Plata, Buenos Aires, Hachette.

Pereyra, Horacio (1960): «Notas sobre la economía del Litoral argentino, 1820-1836». Humanidades, : 35, Facultad de Humanidades y Ciencias de la Educación. Universidad de La Plata.

Pérez Colman, César (1937): Entre Rios. Historia 1520-1810, tomo 3, Paraná, Imprenta de La Provincia.

- (1946): Paraná 1810-1860, los primeros años de la vida nacional, Rosario, Ed. E. Fenner.

Prados de la Escosura, Leandro, y Amaral, Samuel (eds.), (1993): La independencia Americana: consecuencias económicas, Madrid, Ed. Alianza.

Quiroz, Alfonso (1993): «Consecuencias económicas y financieras del proceso de independencia en Perú, 1800-1850», en Prados de la Escosura y Amaral (eds.) cit., pp. 124 146.

ROSAL, Miguel A. (1992 a): «El Río de la Plata en la primera mitad del siglo XIX: las relaciones comerciales entre el Interior y Buenos Aires, 1831-1835», en Boletín del Instituto de Historia Argentina y Americana "Doctor Emilio Ravignani", 3ra. serie: 5. pp. 49-75. Facultad de Filosofía y Letras, Universidad de Buenos Aires.

- (1992 b): «El Río de la Plata en la primera mitad del siglo XIX: las relaciones comerciales entre el Interior y Buenos Aires, 1840-1845 (comparaciones con el período 1831-1835)», en Revista de Historia de América, I.P.G.H. (en prensa). 
- (1993 a): «Las relaciones comerciales entre el Interior y Buenos Aires hacia fines del período rosista» (mimeo).

- (1993 b): «El Interior frente a Buenos Aires; flujos comerciales e integración económica, 1831-1850», Secuencia, México (en prensa).

- (1994): «Flujos comerciales, mercados e integración económica del espacio rioplatense hacia mediados del siglo XIX», Córdoba, en XIV Jornadas de Historia Económica (mimeo).

SalvuCC, Richard, y Salvucci, Linda (1993): «Las consecuencias económicas de la independencia mexicana», en Prados de la Escosura y Amaral (eds.) cit., pp. $31-53$.

Sc:HMIT, Roberto (1991): «Mercados y flujos comerciales en los Estados Provinciales Argentinos de la primera mitad del siglo XIX. El comercio de Corrientes a Buenos Aires (1822-1833)», Boletin del Instituto de Historia Argentina y Americana "Doctor Emilio Ravignani", 3ra. serie: 4, pp. 31-61. Facultad de Filosofía y Letras, Universidad de Buenos Aires.

- (1993): «Mercados y Flujos Comerciales en los Estados Litoraleños Argentinos de la Primera Mitad del Siglo XIX». En: Circuitos mercantiles, mercado y región en Latinoamérica, siglos XVIII-XIX. México, Instituto Mora (en prensa).

SEGRET1, Carlos (1981): La economía del Interior en la primera mitad del siglo XIX (correlación de documentos). I. Cuyo, Buenos Aires, Academia Nacional de la Historia.

Senillosa, Felipe (1835): Memorias sobre los pesos y medidas Buenos Aires.

TANDETLR, Enrique; MilletiCh, Vilma, y SCHMIT, Roberto (1994): «Flujos mercantiles en el Potosí colonial tardío», Anuario IEHS, N. 9, Universidad Nacional del Centro de la Provincia de Buenos Aires.

- 1994: Reproducción en Cinco siglos después: la integración surandina. Cuzco, Centro de estudios regionales andinos «Bartolomé de las Casas» (en prensa)

- Reproducción en Circuitos mercantiles, mercado y región en Latinoamérica, siglos XVIII-XIX. México, Instituto Mora (en prensa).

Urquiza Almandoz, Oscar F. (1978): Historia económica y social de Entre Rios (16001854), Buenos Aires. Ed. Banco Unido del Litoral.

WenTzEl, Claudia (1987): «El comercio del Litoral de los Ríos con Buenos Aires: el área del Paraná 1783-1821», Anuario del Instituto de Estudios Histórico-Sociales (IEHS), : 3 , pp.161-210. Universidad del Centro Prov. de Buenos Aires.

Whilinan, Thomas (1986): «The Politics of River commerce in the Upper Plata 17801865» (Ph.D.diss., Stanford University). Luego editado (1991): The politics of River commerce in the Upper Plata 1780-1870, Albuquerque: University of New Mexico Press. 